\title{
Insights into the Binding and Covalent Inhibition Mechanism of PF- 07321332 to SARS-CoV-2 Mpro
}

\author{
Son Tung Ngo, ${ }^{\text {ab* }}$ Trung Hai Nguyen, ${ }^{\text {ab }}$ Nguyen Thanh Tung, ${ }^{\text {cd }}$ and Binh Khanh Mai ${ }^{*}$ \\ aLaboratory of Theoretical and Computational Biophysics, Ton Duc Thang University, Ho Chi Minh City 72195, \\ Vietnam \\ bFaculty of Applied Sciences, Ton Duc Thang University, Ho Chi Minh City 72195, Vietnam \\ cInstitute of Materials Science, Vietnam Academy of Science and Technology, 11307 Hanoi, Vietnam \\ dGraduate University of Science and Technology, Vietnam Academy of Science and Technology, 11307 Hanoi, Vietnam \\ eDepartment of Chemistry, University of Pittsburgh, Pittsburgh, PA, 15260, USA
}

\begin{abstract}
The severe acute respiratory syndrome coronavirus 2 (SARS-CoV-2) has been causing the COVID-19 pandemic resulting in several million death were reported. Numerous investigations have been carried out to discover a compound that can inhibit the biological activity of SARSCoV-2 main protease, which is an enzyme related to the viral replication. Among these, PF-07321332 is currently under clinical trial for COVID-19 therapy. Therefore, in this work, atomistic and electronic simulations were performed to unravel the binding and covalent inhibition mechanism of the compound to Mpro. Initially, $5 \mu \mathrm{s}$ of steered-molecular dynamics simulations were carried out to evaluate the ligandbinding process to SARS-CoV-2 Mpro. Successfully generated bound state between two molecules showed the important role of the PF-07321332 pyrrolidinyl group and the residues Glu166 and Gln189 in the ligand-binding process. Moreover, from the MD-refined structure, quantum mechanics/molecular mechanics (QM/MM) calculations were carried out to unravel the reaction mechanism for the formation of thioimidate product from SARS-CoV-2 Mpro and PF07321332 inhibitor. We found that the catalytic triad Cys145-His41-Asp187 of SARS-CoV-2 Mpro plays important role in the activation of PF-07321332 covalent inhibitor, which renders the deprotonation of Cys145 and, thus, facilitates further reaction. Our results are definitely beneficial for better understanding on the inhibition mechanism and designing new effective inhibitors for SARSCoV-2 Mpro.
\end{abstract}

\section{INTRODUCTION}

The severe acute respiratory syndrome coronavirus 2 (SARS-CoV-2), a $\beta$-coronavirus belonging to the Coronaviridae virus family, causes the global pandemic named coronavirus disease 2019 (COVID-19). ${ }^{1-3}$ SARS-CoV-2, which was thought to originate from bats, can rapidly transfect between humans and humans. ${ }^{4}$ The virus can be rapidly spread among the community via aerosol transmission.5, 6 Despite international exertions to restrict the spread rate of the virus, the number of infected cases has increasingly raised.7 Moreover, although three vaccines including Pfizer-BioNTech, Moderna, and Janssen COVID19 vaccines were approved by FDA for emergency use, ${ }^{8}$ the pandemic still causes numerous issues to the community health. Especially, the recent work suggested that the longterm health problems of fully recover patients with no or minor symptoms are increasingly recorded. ${ }^{9}$ Furthermore, a growing number of variants escaping from the neutralizing antibodies was observed. ${ }^{10}$, ${ }^{11}$ These variants contain mutations in the piece of the genome encoding the spike protein, which the vaccines were figured to generate immunity. ${ }^{12,13}$ The vaccine effectiveness in the near future will likely be decreased. Therefore, developing an appropriate treatment for COVID-19 is accordingly a great urgency.

The viral genome with $29.2 \mathrm{~kb}$ length encodes more than 20 nonstructural (nsp) and structural proteins., ${ }^{14}$ That of SARS-CoV and SARS-CoV-2 is more than $82 \%$ similar to each other. ${ }^{15}$ In particular, SARS-CoV-2 consists of two proteases including the SARS-CoV-2 main protease (Mpro or ${ }_{3}$ CLpro) and papain-like protease (PLpro), which correspond to nsp5 and nsp3, respectively. The main protease (Mpro) of SARS-CoV-2 virus forms $>96 \%$ sequence identity to the one of SARS-CoV, ${ }^{16},{ }_{17}$ while the SARS-CoV-2 PLpro shares $83 \%$ sequence identity to the SARS-CoV PLpro. ${ }^{18}$ Moreover, the protease first self-cleavage from the productions of the messenger ribonucleic acid (mRNA) translation, and the polyproteins were then cleaved to polypeptides. Because the polypeptides are required for the viral replication and encapsulation, the proteases directly associated with the viral replication and proliferation. ${ }^{16,17}$ More details, PLpro responds for the formation of nsp1-3 and Mpro is respective for the establishment of the nsp4-16.19 Therefore, the SARS-CoV-2 Mpro becomes a high-profile target for antiviral drug design since inhibiting the biological activity of the SARS-CoV-2 Mpro is able to prevent the replication of a new virus.

Although there are already positive signs in developing COVID-19 therapy, ${ }^{20}$ the race for antiviral drugs to prevent COVID-19 continues to be an urgency. ${ }^{21}$ Numerous 
investigations were thus performed to characterize a potential inhibitor for SARS-CoV-2 Mpro..22-34 Several compounds were suggested to be able to inhibit the biological activity of Mpro. In this context, a compound, named PF-07321332, emerges as one of the most potent candidates for an oral antiviral therapeutic factor. The compound is currently under clinical trial phase I as an antiviral agent against SARS-CoV-2 which was shown to be a potential inhibitor for Mpro in vitro studies. 35,36 Moreover, a clinical phase III study in non-hospitalized high-risk adults with COVID-19 is also starting to perform. ${ }^{37}$ Understanding the binding and covalent inhibition mechanism of PF07321332 to SARS-CoV-2 Mpro would be beneficial in the design of antivirus drugs. Therefore, in this work, we tried to reveal the physical insights into the binding and covalent inhibition mechanism of PF-07321332 to SARS-CoV-2 Mpro. The work was supported by steered-molecular dynamics (SMD), and quantum mechanics/molecular mechanics (QM/MM) simulations. In particular, SMD simulations were first employed to preliminarily evaluate the binding pose of the ligand to Mpro. QM/MM calculations then probed the covalent inhibition mechanism. The obtained results are believed to enhance the COVID-19 therapy.

\section{MATERIALS \& METHODS}

\section{Structure of Receptor and Ligand}

The three-dimensional conformation of SARS-CoV-2 Mpro was downloaded from the Protein Data Bank (PDB) with the identity of 7 JYC..$^{8}$ The protonation states of the Mpro catalytic dyad including His41 and Cys145 was assigned as shown in Figure 1A since it plays an important role in the protease activity and ligand effectiveness. 39 The threedimensional structure of PF-07321332 was generated using MarvinSketch, a package of ChemAxon. $4^{\circ}$ The ligand structure was then optimized via density-functional theory (DFT) calculations with B3LYP functional at 6-31G(d,p) level of theory. During QM calculation, the implicit solvent environment, $\varepsilon=78.4$, was implemented.
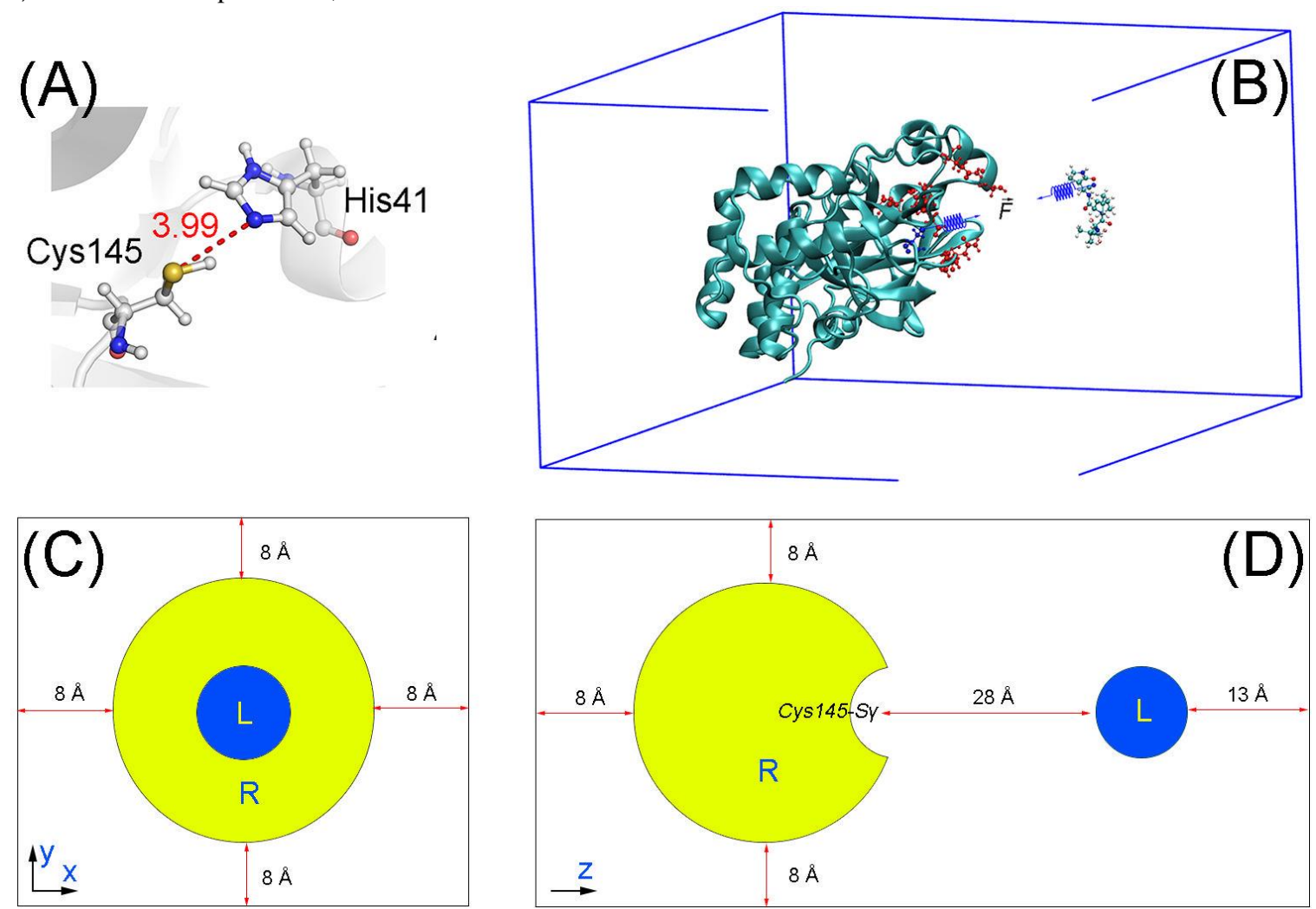

Figure 1. (A) the protonation states of the catalytic dyad. The distance from Cys145-Sy and His41-Ne atoms from the X-ray diffraction structure was also presented. (B) three-dimensional structure of SARS-CoV-2 Mpro (PDB ID 7JYC) + PF-07321332. (B) + (C) system configuration. In particular, the minimum distance between SARS-CoV-2 Mpro Cysi45-Sy and the ligand is ca. $28 \AA$. A constant force with a spring constant cantilever of 1 kcal mol-1 $\AA^{-2}$ was put on SARS-CoV-2 Mpro Cysi45-Sy and the nitrile group of the ligand. The solvent was hidden to clarify the view.

\section{Atomistic Simulations}

Atomistic simulations were performed to obtain the binding pose between SARS-CoV-2 Mpro + PF-07321332 using GROMACS version 2019..$^{41}$ The protease and ions were presented using the Amber14SB force field..$^{22}$ TIP $3 \mathrm{P}$ water model was employed for water molecules. 43 The PF-07321332 was topologized via the general Amber force field 44 with the support of AmberTools18 and ACPYPE packages.45, 46 In particular, the QM calculation using B3LYP functional at 6${ }_{31} \mathrm{G}(\mathrm{d}, \mathrm{p})$ level of theory with the implicit solvent was performed to gain the ligand geometrical information and atomic charges. The restrained electrostatic potential scheme was employed to estimate the ligand atomic charges.44 In particular, the ligand was placed on the position having a minimum distance with the Cys145-Sy atom of $28 \AA$ as mentioned in Error! Reference source not found.. The complex was then inserted into a rectangular periodic boundary condition (PBC) box with a size of $9.40 \times 5.65 \times 8.51 \mathrm{~nm}^{3}$ as shown in Figure 1. The soluble complex contains of 43789 atoms that involving the protease, $\mathrm{PF}-07321332,13012$ water molecules, and 4 ions $\mathrm{Na}^{+}$. 
Atomistic simulations were carried out with the parameters referred to the previous studies.47, 48 The simulations were executed at $310 \mathrm{~K}$. A non-bonded contact between two atoms is available when the pair distance is smaller than $0.9 \mathrm{~nm}$. The electrostatic (cou) and van der Waals (vdW) interactions were computed using the fast Particle-Mesh Ewald electrostatics and cut-off approaches, respectively. 49 The solvated system was first minimized by using the steepest descent method. The minimized system was then relaxed using NVT and NPT simulations with a length of o.1 ns each. During these simulations, SARS-CoV-2 Mpro $C_{\alpha}$ atoms and the ligand atoms were positionally restrained via a small harmonic force having ca. $24 \mathrm{kcal} \mathrm{mol}^{-}$ ${ }^{1} \mathrm{~nm}^{-2}$ spring constant.

\section{Steered-molecular dynamics (SMD) simulations.}

The last conformation of NPT simulations was then used as the starting shape for further SMD simulations. During SMD simulating process, a small constant force with a spring constant of $1 \mathrm{kcal} \mathrm{mol}^{-1} \mathrm{~nm}^{-2}$ was employed to pull the nitrile group of PF-07321332 and the sulfur atom of the residue Cys145 together because a covalent bond is able to form between two groups. $5^{\circ}$ During SMD simulations, the SARSCoV-2 Mpro reorientation and translation were prevented via a small restraining force applying on $C_{\alpha}$ atoms. The ligand was slowly mobilized from unbound to bound states under effects of a small constant force as well as a schematic representation of simulations in Figure 1. It should be noted that using stronger pulling force can make the ligand get into the binding quicker but at the same time may cause distortion to the binding pocket and resulting in the ligand adopting wrong binding poses. We found that the chosen pulling strength is a good trade between computational efficiency and accuracy. Moreover, because the pulling force is very weak, the ligand would mobilize very slowly and probably fail to bind to the active site of the protease. SMD simulation was thus carried out with a length of $50 \mathrm{~ns}$ and repeated 81 times independently to produce the binding conformation of SARS-CoV-2 Mpro + PF-07321332. Besides that, a restraining force with ca. $24 \mathrm{kcal} \mathrm{mol}^{-1} \mathrm{~nm}^{-2}$ spring constant was also applied on SARS-CoV-2 Mpro $C_{\alpha}$ atoms to avoid the system reorientation. Furthermore, a trajectory was extended to 1.0 $\mu \mathrm{s}$ of MD simulations to allow the system enough time to reach the "native" binding pose. There are 5 $\mu$ s of MD simulations totally, which were produced to assess the binding process of PF-07321332 to SARS-CoV-2 Mpro. The coordinates of the complex were recorded every 1 ps.

\section{QM/MM calculation}

The covalent inhibition mechanism for the reaction between PF-07321332 and SARS-CoV-2 Mpro giving thioimidate product was investigated using ONIOM algorithm ${ }^{51}$ implemented in Gaussian 16.52 MolUP package53 was used to support input preparations. A representative snapshot of the SARS-CoV-2 Mpro + PF-07321332 complex in the minimum region of free energy landscape was used as a starting structure for ONIOM calculations (see Results and Discussion section). Only waters and counter-ions within a distance of $7 \AA$ from the protein were kept giving a system with a total of 16327 atoms and a neutral charge. The MM parameters and atomic charges are extracted from the parameter from MD simulations (vide supra). The QM region for ONIOM calculations was defined as shown in Scheme 1, including Cys145, His41, and Asp187 residues. To facilitate the calculations, only part of PF-07321332 that closes to Cys145 is included in the QM region (Scheme 1). Hydrogen-link ( $\mathrm{H}$-link) atoms were added to the QM atoms at the boundary. The QM region has 49 atoms including $\mathrm{H}$ link atoms with a total charge of -1 .

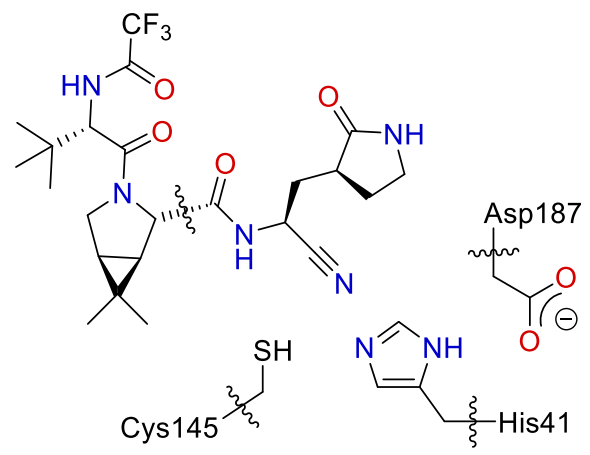

Scheme 1. The definition of QM region for ONIOM calculations.

All intermediates and transition states were fully optimized using the quadratic coupled algorithm ${ }^{54}$ with the dispersion-corrected55 B3LYP functional,56, 57 i.e., B3LYP$\mathrm{D}_{3}(\mathrm{BJ})$, and $6-3 \mathrm{G}(\mathrm{d})$ basis set. All residues in the MM region which are not within $10 \AA$ from the QM region are constrained in all calculations. Vibrational frequency calculations at the same level of theory of the optimization were performed to confirm if each structure is a local minimum (no imaginary frequency) or a transition state (one imaginary frequency). Single-point calculations were carried out using Mo6-2x functional $5^{8}$ and $6-311+G(2 d, 2 p)$ basis set.

\section{Analysis Tools}

The collective variable free energy landscape (FEL) was constructed using "gmx sham", a tool of GROMACS. Two variables are non-hydrogen atom root-mean-square deviation (RMSD) of complex and distance between the sulfur atom of the residue Cys145 and the nitrile group of PF07321332. All of snapshots locating the minima would be used as initials of the clustering analysis. The clustering method was applied with an non-hydrogen RMSD of SARSCoV-2 nine critical residues and the ligand PF-07321332. In particular, nine critical residues are Thr26, His41, Ser46, Asn142, Gly143, Cys145, His164, Glu166, and Gln189, which played an important role in the ligand-binding process of SARS-CoV-2 Mpro.59 The clustering cutoff is of $1 \AA$ A. The protonation states of $\mathrm{PF}-07321332$ were predicted using the chemicalize. ${ }^{60}$

\section{RESULTS AND DISCUSSION}

In this work, SMD simulations were employed to search binding position between PF-07321332 to SARS-CoV-2 Mpro. In particular, the nitrile group of PF-07321332 and the sulfur atom of the residue Cysi45 was pulled together using a small constant force. 81 SMD trajectories with a length of $50 \mathrm{~ns}$ each were produced to investigate the diffusion of PF07321332 around SARS-CoV-2 Mpro active site. Among these, 21 trajectories (26\%) successfully reached the binding pocket since the distance between Cys145-Sy and nonhydrogen atoms of PF-0321332 is less than $4.5 \AA$ (Figures S1S9 of the Supporting Information). However, there only are 13 trajectories $(16 \%)$, where the ligand is stable in the binding pocket until the trajectories were completed. Some trajectories reach the binding pocket just after ca. 4 ns of simulations, whereas some required more than ca. $40 \mathrm{~ns}$. 
Among 21 trajectories mentioned above, 10 of them (12\%) successfully generated the bound states since forming a contact between the Cys145-Sy atom and the nitrile group of PF-07321332, in which the distance $\left(d_{S \gamma-C N}\right)$ is less than 4.5 $\AA$ (Figure $\mathbf{2 A}$ and Figures $\mathbf{S 9}-\mathbf{S}_{\mathbf{1 7}}$ of the Supporting Information). It should be noted that a short contact between two groups would be allowed the nitrile group and the catalytic cysteine to be able to adopt a covalent bond between them. $5^{\circ} \mathrm{PF}-07321332$ required more time (al least ca. $4.5 \mathrm{~ns})$ to reach the bound state after entering the binding pocket of SARS-CoV-2 Mpro. However, there are only 2 trajectories where the $d_{S \gamma-C N}$ stay below $4.5 \AA$ until the

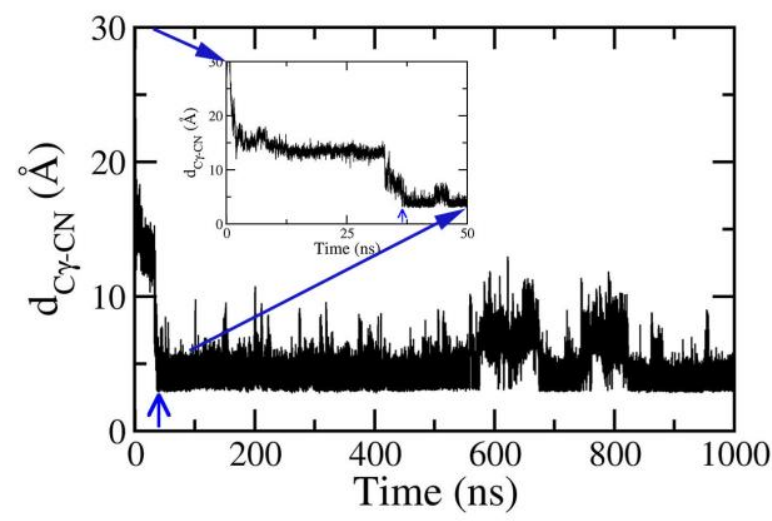

(A)

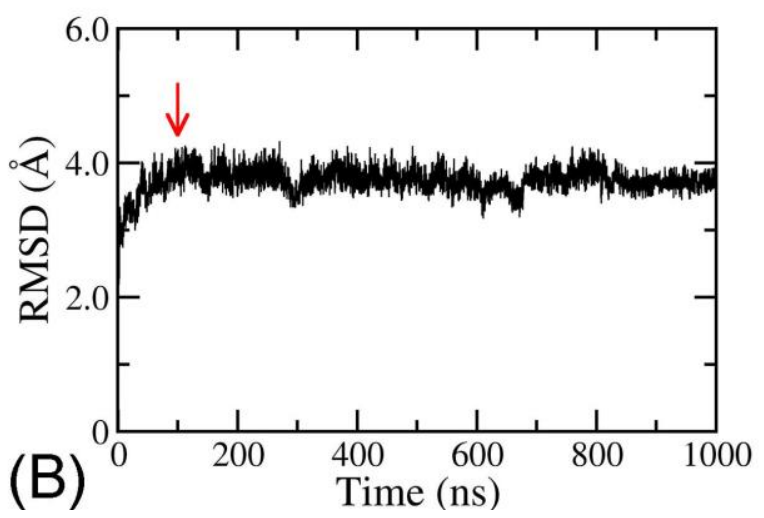

Figure 2. (A) the distance $d_{S \gamma-C N}$ in time dependence. Blue arrow indicates when the ligand PF-07321332 reaches bound state at ca. 36.5 ns. The inset is a zoomed figure over interval o-5o ns. (B) Non-hydrogen RMSD of the complex SARS-CoV-2 Mpro + PFo7321332 over SMD simulations. Red arrow implies when the complex reaches equilibrium states at ca. $100 \mathrm{~ns}$. (C) the collectivevariable FEL was constructed over equilibrium interval 100-1000 ns. Two reaction coordinates were non-hydrogen RMSD of the complex and the distance $d_{S \gamma-C N}$. The minimum denoted as $S_{1}$ at $\left(d_{S \gamma-C N}\right.$, RMSD) coordinates at is $(3.74,3.72)$. (D) is representative structure of the complex, which corresponds to the minimum S1. In particular, the ligand formed HBs to residue Asn142, Glu166, and Q189 (the blue dashed line). The red dashed lines and red numbers denote the distance between two atoms in $\AA$.

Because the nitrile group of PF-07321332 likely forms a covalent bond to the Cys145-Sy atom, in which force constant is much larger than $1 \mathrm{kcal} \mathrm{mol}^{-1} \mathrm{~nm}^{-2}$, one of the successfully generated bound state trajectories was extended to $1 \mu \mathrm{s}$ to assess the stability of the complex. The nonhydrogen RMSD of the complex reaches stable states after ca. 100 ns of SMD simulations (Figure 2B). 900.000 simulations were completed (Movie S1 describes a representative binding process). Moreover, although the binding mechanism of PF-07321332 probably is a complex pathway instead of a simple mobilization of the ligand to the pocket, ${ }^{61}$ two successfully generated bound states trajectories preliminarily suggested that the residues Glu166 and Glnı89 play an important role during the binding process of the inhibitor (Figures S18-S19 of the Supporting Information). Furthermore, analyzing two trajectories indicated that the pyrrolidinyl group of the ligand first inserted itself into the space between the residues Glu166 and Gln189, before the whole of PF-07321332 fully inserted into the binding pocket of SARS-CoV-2 Mpro.
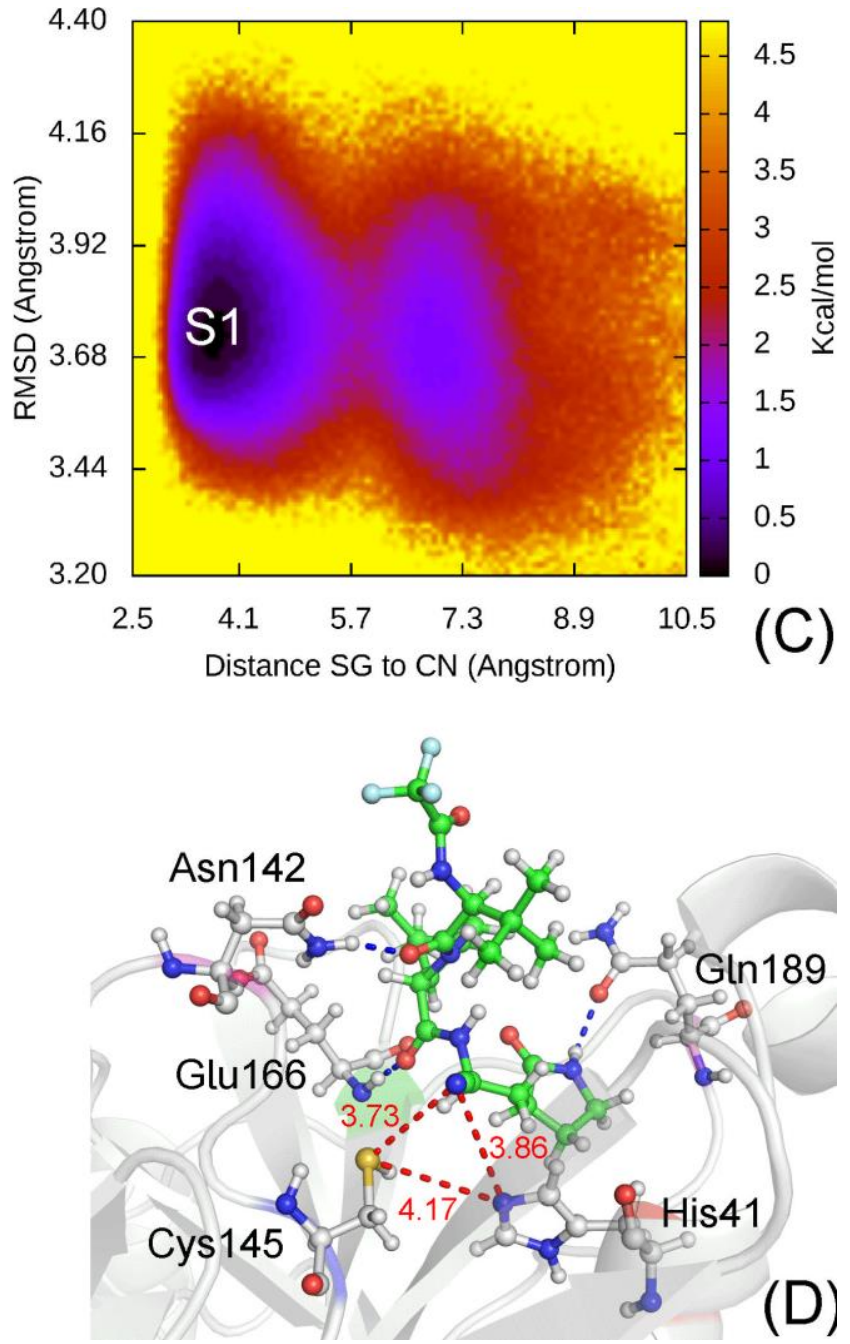
structure S1 was shown in Figure 2D. In particular, the ligand nitrile group formed a contact with the Cys145-SY atom at a distance of $d_{S \gamma-C N}=3.73 \AA$. The ligand nitrile group also adopted a contact with the His-N $\varepsilon$ atom with an amount of $d_{N \varepsilon-C N}=3.86 \AA$. The presence of contacts between the PF-0721332 nitrile group increases the distance between the Cys145-Sy and His41-E $\varepsilon$ atoms $d_{N \varepsilon-S \gamma}$ from 3.99 to $4.17 \AA$ (Figures $\mathbf{1 A}$ and 2D). Therefore, the catalytic dyad Cys145-His41 is probably disturbed. Besides, the ligand also formed HBs to three residues including Asn142, Glu166, and Glnı89 (Figure 2D).

In recent theoretical studies, ${ }^{62-66}$ sing adaptive string method, Moliner and Tuñon et al proposed that the catalytic dyad $\mathrm{Cys} 145 \mathrm{H}-\mathrm{His} 41$ plays an important role in the reactivity of SARS-CoV-2 Mpro, where a proton transfer from $\mathrm{Cys} 145 \mathrm{H}$ to His41 takes place first giving ion pair Cys145--His $41 \mathrm{H}^{+}$, which is followed by a nucleophilic addition producing covalent bond with inhibitor. In our initial ONIOM calculations, only residues Cys145, His41, and PF-0721332 inhibitor were included in the QM region. However, we were unsuccessful in locating the ion-pair Cys $145^{-}-\mathrm{His} 41 \mathrm{H}^{+}$. During the optimization, the proton automatically transfers from His41 $\mathrm{H}^{+}$to Cys145- (see Figure S2o of the Supporting Information). We then performed a constrained optimization by fixing the $\mathrm{N}-\mathrm{H}$ distances to $1.01 \AA$. Interstingly, the ion pair structure is calculated to be 31.6 kcal mol-1 than the neutral form (Scheme 2). Our DFT calculations suggest that the imidazole ring of His41 is not basic enough to abstract proton from thiol group of Cys145.

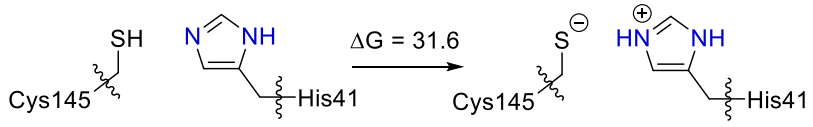

Scheme 2. Computed free energy difference $\left(\mathrm{kcal} \mathrm{mol}^{-1}\right)$ for the ion pair formation of catalytic dyad $\left(\mathrm{Cys}_{4} 45^{-}-\mathrm{His}_{41} \mathrm{H}^{+}\right)$ from the neutral form (Cys145H-His41).

Searching for alternative mechanisms for this reaction, we found that the residue Asp187 is close to the residue His41, which can form a catalytic triad ${ }^{6}{ }_{7}$ Cys145-His41-Asp187 facilitating for the deprotonation of Cys145. Therefore, Asp187 residue is then included in our ONIOM calculations. The computed free energy profile for the covalent inhibition mechanism between SARS-CoV-2 Mpro and PF-0721332 is shown in Figure 3. At Int-1, a strong hydrogen bond with a distance of $1.64 \AA$ between His41 and Asp187 is found. A proton transfer via TS-1 between His41 and Asp187 can easily take place giving His $41^{-}$, which is followed by another proton transfer via TS-2 from Cys145 to His41 ${ }^{-}$generating Cys145 ${ }^{-}$. The activation barriers of two proton transfers TS-1 and TS2 steps are very low, amounting to 0.7 and $3.4 \mathrm{kcal} \mathrm{mol}^{-1}$, respectively, relative to Int-1. It should be noted that albeit the electronic energy of TS-1 is calculated to be $0.5 \mathrm{kcal} / \mathrm{mol}$ higher than Int-2, because of the entropic effect, Gibbs free energy value of TS-1 is slightly lower than Int-2 (Figure 3). 
(A)

$\left.\uparrow_{\Delta \mathrm{G}} \mathrm{kcal} / \mathrm{mol}\right)$

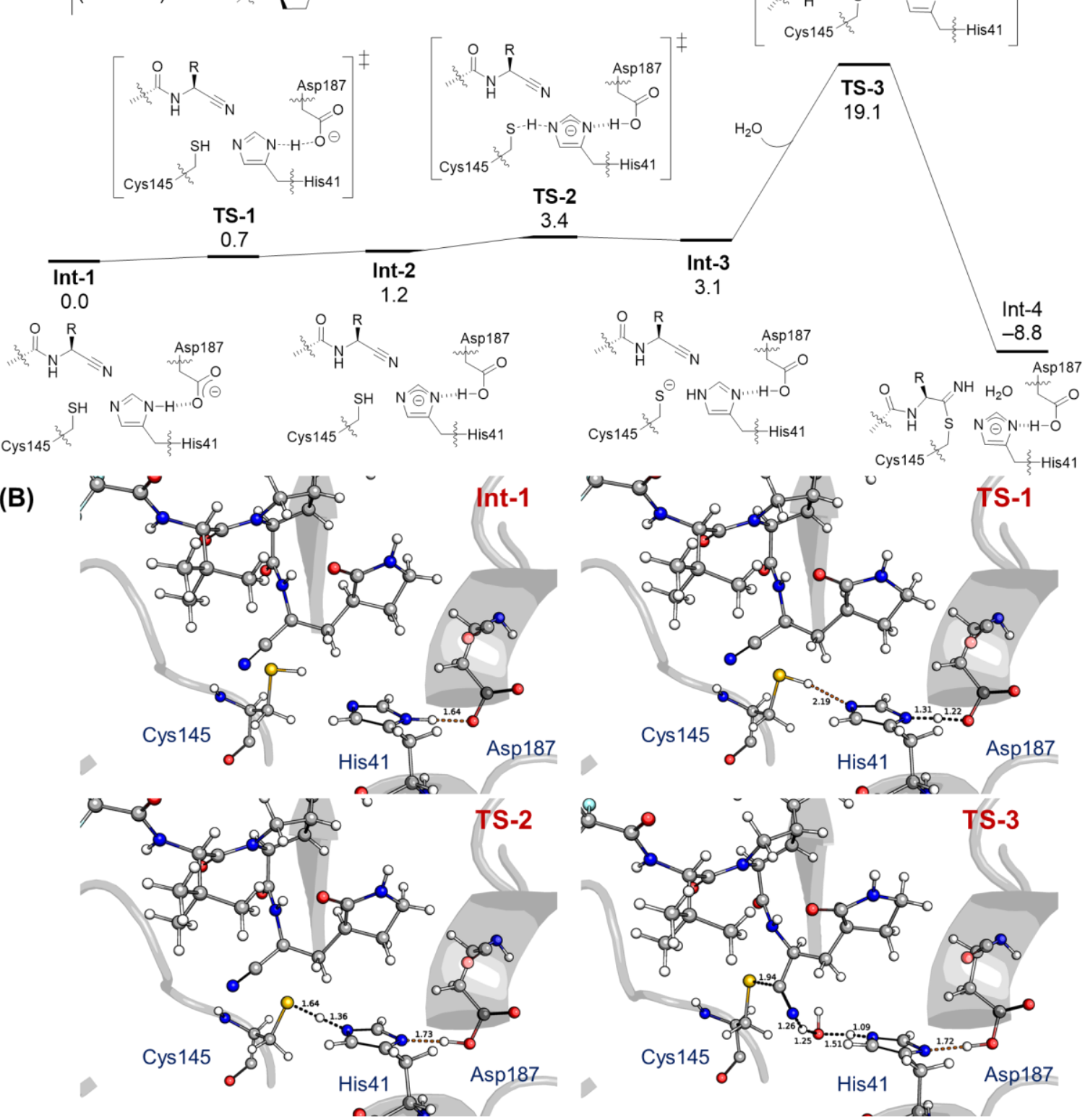

Figure 3. Computed free energy profile (in $\mathrm{kcal} \mathrm{mol}^{-1}$ ) and optimized structures of reactant complex and transition states for the covalent inhibition mechanism of PF-07321332 with SARS-CoV-2 Mpro. All distances are given in $\AA$.

From Int-2, nucleophilic addition of Cys145- to the nitrile warhead of PF-07321332 via TS-3 can then take place. Interestingly, at TS-3, a water molecule is crucial to stabilize the developed negative charge on the nitrogen atom of the nitrile group resulting from the nucleophilic addition of Cys145-. The small size of the nitrile warhead allows for the water molecule to participate in the reaction and transfer proton from His47 to nitrogen atom. We have also tried to optimize the nucleophilic addition without a water molecule. However, no TS can be located. The activation barrier of TS-3 is calculated to be $19.1 \mathrm{kcal} \mathrm{mol}^{-1}$ relative to Int-1, which is consistent with the previous study by Tuñón and co-workers. ${ }^{66}$ Our reaction mechanism is in good agreement with the covalent inhibition mechanism of antidiabetic drugs in dipeptidyl peptidase- $4 .{ }^{68}$

It should be mention that from Int-4, the hydrolysis of the $\mathrm{S}-\mathrm{C}$ bond can also occur by the nucleophilic addition of water to form an amide product. (Figure S21 of the Supporting Information for the optimized transition state)). However, this transition state is calculated to be $39.6 \mathrm{kcal}$ mol $^{-1}$ relative to Int-3 ruling out this possibility and validating the inhibition ability of PF-07321332 to SARS-CoV2 Mpro.

Based on our ONIOM calculations, we found that the catalytic triad Cys145-His41-Asp187 plays important role in the covalent inhibition of SARS-CoV-2 Mpro, which enables the deprotonation of Cys145 and, thus, facilitats for further reaction. This finding is consistent with the previous study 69 which demonstrated that Asp187 favors the proton transfer from Cys145 to His41.

\section{CONCLUSIONS}

In this work, $5 \mu$ s of SMD simulations were first generated to preliminarily estimate the binding pose of PF-07321332 to 
SARS-CoV-2 Mpro. In particular, the ligand reached the binding pocket of SARS-CoV-2 Mpro in $26 \%$ trajectories. Among these, the nitrile group of PF-07321332 successfully adopted a contact with the Cys145-Sy atom over $12 \%$ trajectories. However, the contact only stabilizes over 2 trajectories until the simulations were completed. Moreover, the residues Glu166 and Gln189 were suggested that they play an important role during the binding process of the inhibitor. The pyrrolidinyl group of PF-07321332 probably is a key leading the compound into a successful bound state.

A representative structure of SARS-CoV-2 Mpro + PF07321332 were obtained by using a combined calculation FEL and clustering analyses. In this state, the distance between the Cys145-Sy and His41-Ec atoms $d_{N \varepsilon-S \gamma}$ was increased from 3.99 to $4.17 \AA$ when the PF-07321332 nitrile group adopted a contact with the Cys145-Sy atom $\left(d_{S \gamma-C N}=3.73 \AA\right)$. The catalytic dyad Cys145-His41 is probably disturbed. Besides, three residues Asnı42, Glu166, and Gln189 play a crucial factor in the ligand-binding process since forming HBs to the inhibitor.

From the representative structure of the complex, quantum mechanics/molecular mechanics (QM/MM) calculations were performed to unravel the reaction mechanism for the formation of thioimidate product from SARS-CoV-2 Mpro and PF-07321332 inhibitor. We found that the catalytic triad Cys145-His41-Asp187 of SARS-CoV-2 Mpro plays important role in the activation of PF-07321332 covalent inhibitor, which renders the deprotonation of Cys145 and, thus, facilitates further reaction. The outcome is in good agreement with the previous study ${ }^{6}$ which found that Asp187 favors the proton transfer from Cys145 to His41. Our results are definitely beneficial for better understanding on the inhibition mechanism and designing new effective inhibitors for SARS-CoV-2 Mpro.

\section{ASSOCIATED CONTENT}

\section{Supporting Information}

Supporting Information Available: the minimum distance between non-hydrogen atoms of PF-07321332 and nonhydrogen atoms of the catalytic dyad, the minimum distance $d_{S \gamma-C N}$ between the nitrile group of PF-07321332 and the sulfur atom of the residue Cys145, the binding pathway of PF-07321332 to SARS-CoV-2 Mpro over the trajectories o and 20, the optimization starting from ion-pair Cys $145^{-}-\mathrm{His}_{4} 1 \mathrm{H}^{+}$, the optimized transition state for the hydrolysis of Int-3, and energy and cartesian coordinate.

\section{AUTHOR INFORMATION}

\section{Corresponding Author}

*Email: ngosontung@tdtu.edu.vn and binh.mai@pitt.edu

\section{Author Contributions}

All authors contributed to writing the manuscript.

\section{Notes}

The authors declare no competing financial interests. ACKNOWLEDGMENT

This work was supported by Vietnam National Foundation for Science \& Technology Development (NAFOSTED) grant \#104.99-2019.57.

\section{REFERENCES}

1. Wu, F.; Zhao, S.; Yu, B.; Chen, Y.-M.; Wang, W.; Song, Z.-G.; Hu, Y.; Tao, Z.-W.; Tian, J.-H.; Pei, Y.-Y.; Yuan, M.L.; Zhang, Y.-L.; Dai, F.-H.; Liu, Y.; Wang, Q.-M.; Zheng, J.-J.; $\mathrm{Xu}$, L.; Holmes, E. C.; Zhang, Y.-Z., A New Coronavirus Associated with Human Respiratory Disease in China. Nature 2020, 579 (7798), 265-269.

2. Gorbalenya, A. E.; Baker, S. C.; Baric, R. S.; de Groot, R. J.; Drosten, C.; Gulyaeva, A. A.; Haagmans, B. L.; Lauber, C.; Leontovich, A. M.; Neuman, B. W.; Penzar, D.; Perlman, S.; Poon, L. L. M.; Samborskiy, D. V.; Sidorov, I. A.; Sola, I.; Ziebuhr, J.; Coronaviridae Study Group of the International Committee on Taxonomy of, V., The species Severe acute respiratory syndrome-related coronavirus: classifying 2019$\mathrm{nCoV}$ and naming it SARS-CoV-2. Nat Microbiol 2020, 5 (4), 536-544.

3. WHO Director-General's opening remarks at the media briefing on COVID-19 - 11 March 2020. https://www.who.int/director-

general/speeches/detail/who-director-general-s-openingremarks-at-the-media-briefing-on-covid-19---11-march$\underline{2020}$.

4. $\quad$ Chan, J. F. W.; Yuan, S. F.; Kok, K. H.; To, K. K. W.; Chu, H.; Yang, J.; Xing, F. F.; Liu, J. L.; Yip, C. C. Y.; Poon, R. W. S.; Tsoi, H. W.; Lo, S. K. F.; Chan, K. H.; Poon, V. K. M.; Chan, W. M.; Ip, J. D.; Cai, J. P.; Cheng, V. C. C.; Chen, H. L.; Hui, C. K. M.; Yuen, K. Y., A Familial Cluster of Pneumonia Associated with the 2019 Novel Coronavirus Indicating Person-toPerson Transmission: a Study of a Family Cluster. Lancet 2020, 395 (10223), 514-523.

5. $\quad$ Greenhalgh, T.; Jimenez, J. L.; Prather, K. A.; Tufekci, Z.; Fisman, D.; Schooley, R., Ten Scientific Reasons in Support of Airborne Transmission of SARS-CoV-2. Lancet 2021, 397 (10285), 1603-1605.

6. van Doremalen, N.; Bushmaker, T.; Morris, D. H.; Holbrook, M. G.; Gamble, A.; Williamson, B. N.; Tamin, A.; Harcourt, J. L.; Thornburg, N. J.; Gerber, S. I.; Lloyd-Smith, J. O.; de Wit, E.; Munster, V. J., Aerosol and Surface Stability of SARS-CoV-2 as Compared with SARS-CoV-1. $N$ Engl J Med 2020, 382, 1564-1567.

7. worldometrics COVID-19 Coronavirus Pandemic. https://www.worldometers.info/coronavirus/.

8. COVID-19 Vaccines.

https://www.fda.gov/emergency-preparedness-andresponse/coronavirus-disease-2019-covid-19/covid-19vaccines (accessed Jan 08).

9. Augustin, M.; Schommers, P.; Stecher, M.; Dewald, F.; Gieselmann, L.; Gruell, H.; Horn, C.; Vanshylla, K.; Cristanziano, V. D.; Osebold, L.; Roventa, M.; Riaz, T.; Tschernoster, N.; Altmueller, J.; Rose, L.; Salomon, S.; Priesner, V.; Luers, J. C.; Albus, C.; Rosenkranz, S.; Gathof, B.; Fätkenheuer, G.; Hallek, M.; Klein, F.; Suárez, I.; Lehmann, C., Post-COVID syndrome in non-hospitalised patients with COVID-19: a longitudinal prospective cohort study. The Lancet Regional Health - Europe 2021, 6.

10. Wang, P.; Nair, M. S.; Liu, L.; Iketani, S.; Luo, Y.; Guo, Y.; Wang, M.; Yu, J.; Zhang, B.; Kwong, P. D.; Graham, B. S.; Mascola, J. R.; Chang, J. Y.; Yin, M. T.; Sobieszczyk, M.; Kyratsous, C. A.; Shapiro, L.; Sheng, Z.; Huang, Y.; Ho, D. D., Antibody Resistance of SARS-CoV-2 Variants B.1.351 and B.1.1.7. Nature 2021.

11. Hoffmann, M.; Arora, P.; Groß, R.; Seidel, A.; Hörnich, B. F.; Hahn, A. S.; Krüger, N.; Graichen, L.; HofmannWinkler, H.; Kempf, A.; Winkler, M. S.; Schulz, S.; Jäck, H.-M.; Jahrsdörfer, B.; Schrezenmeier, H.; Müller, M.; Kleger, A.; Münch, J.; Pöhlmann, S., SARS-CoV-2 Variants B.1.351 and P.1 Escape from Neutralizing Antibodies. Cell 2021, 184 (9), 2384-2393. 
12. South African SARS-CoV-2 Variant Alarms Scientists. https://www.the-scientist.com/newsopinion/south-african-sars-cov-2-variant-alarms-scientists68317 (accessed Jan 08).

13. Tu, H.; Avenarius, M. R.; Kubatko, L.; Hunt, M.; Pan, X.; Ru, P.; Garee, J.; Thomas, K.; Mohler, P.; Pancholi, P.; Jones, D., Distinct Patterns of Emergence of SARS-CoV-2 Spike Variants including N501Y in Clinical Samples in Columbus Ohio. bioRxiv 2021, 2021.01.12.426407.

14. Francés-Monerris, A.; Hognon, C.; Miclot, T.; García-Iriepa, C.; Iriepa, I.; Terenzi, A.; Grandemange, S.; Barone, G.; Marazzi, M.; Monari, A., Molecular Basis of SARSCoV-2 Infection and Rational Design of Potential Antiviral Agents: Modeling and Simulation Approaches. J. Proteome Res. 2020, 19 (11), 4291-4315.

15. WHO Coronavirus disease 2019 (COVID-19) Situation Report - 52.

16. Fauquet, C. M.; Fargette, D., International Committee on Taxonomy of Viruses and the 3,142 unassigned species. Virology 2005, 2 (1), 64.

17. Alex, Z.; Vladimir, A.; Alexander, Z.; Bogdan, Z.; Victor, T.; Dmitry S., B.; Daniil, P.; Rim, S.; Andrey, F.; Philipp, O.; Yilin, Y.; Olga, P.; Quentin, V.; Alex, A.; Yan, I., Potential COVID-2019 3C-like Protease Inhibitors Designed Using Generative Deep Learning Approaches. 2020.

18. Shin, D.; Mukherjee, R.; Grewe, D.; Bojkova, D.; Baek, K.; Bhattacharya, A.; Schulz, L.; Widera, M.; Mehdipour, A. R.; Tascher, G.; Geurink, P. P.; Wilhelm, A.; van der Heden van Noort, G. J.; Ovaa, H.; Müller, S.; Knobeloch, K.-P.; Rajalingam, K.; Schulman, B. A.; Cinatl, J.; Hummer, G.; Ciesek, S.; Dikic, I., Papain-Like Protease Regulates SARS-CoV2 Viral Spread and Innate Immunity. Nature 2020, 587 (7835), 657-662.

19. Freitas, B. T.; Durie, I. A.; Murray, J.; Longo, J. E.; Miller, H. C.; Crich, D.; Hogan, R. J.; Tripp, R. A.; Pegan, S. D., Characterization and Noncovalent Inhibition of the Deubiquitinase and deISGylase Activity of SARS-CoV-2 Papain-Like Protease. ACS Infect. Dis. 2020, 6 (8), 2099-2109. 20. FDA Approves First Treatment for COVID-19. https://www.fda.gov/news-events/press-

announcements/fda-approves-first-treatment-covid19?fbclid=IwAR3jElh3p4H0YrLtL0o920E931R6ygixc2edh3 zPX4E6SL4AbmMFNu19q8U (accessed Oct 27).

21. Dolgin, E., The race for antiviral drugs to beat COVID - and the next pandemic. Nature 2021, 592, 340-343.

22. Komatsu, T. S.; Okimoto, N.; Koyama, Y. M.; Hirano, Y.; Morimoto, G.; Ohno, Y.; Taiji, M., Drug binding dynamics of the dimeric SARS-CoV-2 main protease, determined by molecular dynamics simulation. Sci Rep 2020, 10 (1), 16986. 23. Sacco, M. D.; Ma, C.; Lagarias, P.; Gao, A.; Townsend, J. A.; Meng, X.; Dube, P.; Zhang, X.; Hu, Y.; Kitamura, N.; Hurst, B.; Tarbet, B.; Marty, M. T.; Kolocouris, A.; Xiang, Y.; Chen, Y.; Wang, J., Structure and inhibition of the SARS-CoV-2 main protease reveal strategy for developing dual inhibitors against $\mathrm{M}<$ sup $>$ pro</sup $>$ and cathepsin L. Sci Adv 2020, 6 (50), eabe0751.

24. Vuong, W.; Khan, M. B.; Fischer, C.; Arutyunova, E.; Lamer, T.; Shields, J.; Saffran, H. A.; McKay, R. T.; van Belkum, M. J.; Joyce, M. A.; Young, H. S.; Tyrrell, D. L.; Vederas, J. C.; Lemieux, M. J., Feline coronavirus drug inhibits the main protease of SARS-CoV-2 and blocks virus replication. Nature Communications 2020, 11 (1), 4282.

25. Li, Z.; Li, X.; Huang, Y.-Y.; Wu, Y.; Liu, R.; Zhou, L.; Lin, Y.; Wu, D.; Zhang, L.; Liu, H.; Xu, X.; Yu, K.; Zhang, Y.; Cui, J.; Zhan, C.-G.; Wang, X.; Luo, H.-B., Identify Potent SARSCoV-2 Main Protease Inhibitors via Accelerated Free Energy
Perturbation-Based Virtual Screening of Existing Drugs. Proc. Natl. Acad. Sci. U.S.A 2020, 117 (44), 27381-27387.

26. Ma, C.; Sacco, M. D.; Hurst, B.; Townsend, J. A.; Hu, Y.; Szeto, T.; Zhang, X.; Tarbet, B.; Marty, M. T.; Chen, Y.; Wang, J., Boceprevir, GC-376, and calpain inhibitors II, XII inhibit SARS-CoV-2 viral replication by targeting the viral main protease. Cell Res 2020, 30 (8), 678-692.

27. Dai, W.; Zhang, B.; Su, H.; Li, J.; Zhao, Y.; Xie, X.; Jin, Z.; Liu, F.; Li, C.; Li, Y.; Bai, F.; Wang, H.; Cheng, X.; Cen, X.; Hu, S.; Yang, X.; Wang, J.; Liu, X.; Xiao, G.; Jiang, H.; Rao, Z.; Zhang, L.-K.; Xu, Y.; Yang, H.; Liu, H., Structure-based Design of Antiviral Drug Candidates Targeting the SARS-CoV-2 Main Protease. Science 2020, 368, 1331-1335.

28. Pham, M. Q.; Vu, K. B.; Han Pham, T. N.; Thuy Huong, L. T.; Tran, L. H.; Tung, N. T.; Vu, V. V.; Nguyen, T. H.; Ngo, S. T., Rapid prediction of possible inhibitors for SARSCoV-2 main protease using docking and FPL simulations. RSC Adv 2020, 10 (53), 31991-31996.

$29 . \quad$ Ngo, S. T.; Hung Minh, N.; Le Thi Thuy, H.; Pham Minh, Q.; Vi Khanh, T.; Nguyen Thanh, T.; Van, V., Assessing Potential Inhibitors for SARS-CoV-2 Main Protease from Available Drugs using Free Energy Perturbation Simulations. RSC Adv 2020, 10, 40284-40290.

30. Jin, Z.; Du, X.; Xu, Y.; Deng, Y.; Liu, M.; Zhao, Y.; Zhang, B.; Li, X.; Zhang, L.; Peng, C.; Duan, Y.; Yu, J.; Wang, L.; Yang, K.; Liu, F.; Jiang, R.; Yang, X.; You, T.; Liu, X.; Yang, X.; Bai, F.; Liu, H.; Liu, X.; Guddat, L. W.; Xu, W.; Xiao, G.; Qin, C.; Shi, Z.; Jiang, H.; Rao, Z.; Yang, H., Structure of Mpro from SARS-CoV-2 and Discovery of its Inhibitors. Nature 2020, 582 (7811), 289-293.

31. Jin, Z.; Zhao, Y.; Sun, Y.; Zhang, B.; Wang, H.; Wu, Y.; Zhu, Y.; Zhu, C.; Hu, T.; Du, X.; Duan, Y.; Yu, J.; Yang, X.; Yang, X.; Yang, K.; Liu, X.; Guddat, L. W.; Xiao, G.; Zhang, L.; Yang, H.; Rao, Z., Structural Basis for the Inhibition of SARSCoV-2 Main protease by Antineoplastic Drug Carmofur. Nat Struct Mol Biol 2020, 27, 529-532.

32. Zhang, L.; Lin, D.; Sun, X.; Curth, U.; Drosten, C.; Sauerhering, L.; Becker, S.; Rox, K.; Hilgenfeld, R., Crystal Structure of SARS-CoV-2 Main Protease Provides a Basis for Design of Improved $\alpha$-Ketoamide Inhibitors. Science 2020, 368, 409-412.

33. Tam, N. M.; Pham, M. Q.; Ha, N. X.; Nam, P. C.; Phung, H. T. T., Computational Estimation of Potential Inhibitors from Known Drugs Against the Main Protease of SARS-CoV-2. RSC Adv 2021, 11 (28), 17478-17486.

34. Ngo, S. T.; Quynh Anh Pham, N.; Thi Le, L.; Pham, D.-H.; Vu, V. V., Computational Determination of Potential Inhibitors of SARS-CoV-2 Main Protease. J. Chem. Inf. Model. 2020, 60 (12), 5771-5780.

35. Study of PF-07321332 in Healthy Participants. https://clinicaltrials.gov/ct2/show/NCT04756531

(accessed Jun 17).

36. Pfizer Initiates Phase 1 Study of Novel Oral Antiviral Therapeutic Agent Against SARS-CoV-2. https://www.pfizer.com/news/press-release/pressrelease-detail/pfizer-initiates-phase-1-study-novel-oralantiviral (accessed Jun 17).

37. A Study of PF-07321332/Ritonavir in Nonhospitalized High Risk Adult Participants With COVID-19. https://clinicaltrials.gov/ct2/show/NCT04960202

(accessed Sep 03).

38. Andi, B.; Kumaran, D.; Kreitler, D. F.; Soares, A. S.; Shi, W.; Jakoncic, J.; Fuchs, M. R.; Keereetaweep, J.; Shanklin, J.; McSweeney, S. Hepatitis C Virus NSP3/NSP4A Inhibitors as Promising Lead Compounds for the Design of New Covalent Inhibitors for SARS-CoV-2 3CLpro/Mpro Protease. (accessed Oct 04). 
39. Carlos A., R.-G.; J. Javier, R.-P.; Iñaki, T., Multiscale Simulations of SARS-CoV-2 3CL Protease Inhibition with Aldehyde Derivatives. Role of Protein and Inhibitor Conformational Dynamics in the Reaction Mechanism. 2020. 40. Marvin was Used for Drawing, Displaying and Characterizing Chemical Structures, Substructures and Reactions, Marvin 20.8.0, 2020, ChemAxon. http://www.chemaxon.com.

41. Abraham, M. J.; Murtola, T.; Schulz, R.; Páll, S.; Smith, J. C.; Hess, B.; Lindahl, E., GROMACS: High Performance Molecular Simulations through Multi-Level Parallelism from Laptops to Supercomputers. SoftwareX 2015, 1-2, 19-25.

42. Maier, J. A.; Martinez, C.; Kasavajhala, K.; Wickstrom, L.; Hauser, K. E.; Simmerling, C., ff14SB: Improving the Accuracy of Protein Side Chain and Backbone Parameters from ff99SB. J. Chem. Theor. Compt 2015, 11 (8), 3696-3713.

43. Jorgensen, W. L.; Chandrasekhar, J.; Madura, J. D.; Impey, R. W.; Klein, M. L., Comparison of Simple Potential Functions for Simulating Liquid Water. J. Chem. Phys. 1983, 79 (2), 926-935.

44. Wang, J.; Wolf, R. M.; Caldwell, J. W.; Kollman, P. A.; Case, D. A., Development and Testing of a General Amber Force Field. J. Comput. Chem. 2004, 25 (9), 1157-1174.

45. Case, D. A.; Ben-Shalom, I. Y.; Brozell, S. R.; Cerutti, D. S.; Cheatham, T. E. C., III, V.W.D. ; Darden, T. A.; Duke, R. E.; Ghoreishi, D.; Gilson, M. K.; Gohlke, H.; Goetz, A. W.; Greene, D.; Harris, R.; Homeyer, N.; Huang, Y.; Izadi, S.; Kovalenko, A.; Kurtzman, T.; Lee, T. S.; LeGrand, S.; Li, P.; Lin, C.; Liu, J.; Luchko, T.; Luo, R.; Mermelstein, D. J.; Merz, K. M.; Miao, Y.; Monard, G.; Nguyen, C.; Nguyen, H.; Omelyan, I.; Onufriev, A.; Pan, F.; Qi, R.; Roe, D. R.; Roitberg, A.; Sagui, C.; Schott-Verdugo, S.; Shen, J.; Simmerling, C. L.; Smith, J.; SalomonFerrer, R.; Swails, J.; Walker, R. C.; Wang, J.; Wei, H.; Wolf, R. M.; Wu, X.; Xiao, L.; D.M., Y.; P.A., a. K., AMBER 18. University of California, San Francisco 2018.

46. Sousa da Silva, A. W.; Vranken, W. F., ACPYPE AnteChamber PYthon Parser interfacE. BMC Research Notes 2012, 5 (1), 1-8.

47. Ngo, S. T.; Nguyen, T. H.; Tung, N. T.; Nam, P. C.; Vu, K. B.; Vu, V. V., Oversampling Free Energy Perturbation Simulation in Determination of the Ligand-Binding Free Energy. J. Comput. Chem 2020, 41 (7), 611-618.

48. Ngo, S. T.; Vu, K. B.; Bui, L. M.; Vu, V. V., Effective Estimation of Ligand-Binding Affinity Using Biased Sampling Method. ACS Omega 2019, 4 (2), 3887-3893.

49. Darden, T.; York, D.; Pedersen, L., Particle mesh Ewald: $A n N \cdot \log (\mathrm{N})$ method for Ewald sums in large systems. J. Chem. Phys. 1993, 98 (12), 10089-10092.

50. Löser, R.; Schilling, K.; Dimmig, E.; Gütschow, M., Interaction of Papain-like Cysteine Proteases with DipeptideDerived Nitriles. J. Med. Chem 2005, 48 (24), 7688-7707.

51. Chung, L. W.; Sameera, W. M. C.; Ramozzi, R.; Page, A. J.; Hatanaka, M.; Petrova, G. P.; Harris, T. V.; Li, X.; Ke, Z.; Liu, F.; Li, H.-B.; Ding, L.; Morokuma, K., The ONIOM Method and Its Applications. Chem Rev 2015, 115 (12), 5678-5796.

52. Frisch, M. J.; Trucks, G. W.; Schlegel, H. B.; Scuseria, G. E.; Robb, M. A.; Cheeseman, J. R.; Scalmani, G.; Barone, V.; Petersson, G. A.; Nakatsuji, H.; Li, X.; Caricato, M.; Marenich, A. V.; Bloino, J.; Janesko, B. G.; Gomperts, R.; Mennucci, B.; Hratchian, H. P.; Ortiz, J. V.; Izmaylov, A. F.; Sonnenberg, J. L.; Williams; Ding, F.; Lipparini, F.; Egidi, F.; Goings, J.; Peng, B.; Petrone, A.; Henderson, T.; Ranasinghe, D.; Zakrzewski, V. G.; Gao, J.; Rega, N.; Zheng, G.; Liang, W.; Hada, M.; Ehara, M.; Toyota, K.; Fukuda, R.; Hasegawa, J.; Ishida, M.; Nakajima, T.; Honda, Y.; Kitao, O.; Nakai, H.; Vreven, T.; Throssell, K.; Montgomery Jr., J. A.; Peralta, J. E.; Ogliaro, F.; Bearpark, M.
J.; Heyd, J. J.; Brothers, E. N.; Kudin, K. N.; Staroverov, V. N.; Keith, T. A.; Kobayashi, R.; Normand, J.; Raghavacha-ri, K.; Rendell, A. P.; Burant, J. C.; Iyengar, S. S.; Tomasi, J.; Cossi, M.; Millam, J. M.; Klene, M.; Adamo, C.; Cammi, R.; Ochterski, J. W.; Martin, R. L.; Morokuma, K.; Farkas, O.; Foresman, J. B.; Fox, D. J. Gaussian 16 Rev. C.012016.

53. S. Fernandes, H.; Ramos, M. J.; M. F. S. A. Cerqueira, N., molUP: A VMD plugin to handle QM and ONIOM calculations using the gaussian software. J. Comput. Chem 2018, 39 (19), 1344-1353.

54. $\quad$ Vreven, T.; Frisch, M. J.; Kudin, K. N.; Schlegel, H. B.; Morokuma, K., Geometry optimization with QM/MM methods II: Explicit quadratic coupling. Mol. Phys. 2006, 104 (5-7), 701-714.

55. Grimme, S.; Ehrlich, S.; Goerigk, L., Effect of the damping function in dispersion corrected density functional theory. J. Comput Chem 2011, 32 (7), 1456-1465.

56. Lee, C.; Yang, W.; Parr, R. G., Development of the Colle-Salvetti correlation-energy formula into a functional of the electron density. Phys Rev B 1988, 37 (2), 785-789.

57. Becke, A. D., Density-functional thermochemistry. III. The role of exact exchange. J. Chem. Phys. 1993, 98 (7), 5648-5652.

58. Zhao, Y.; Truhlar, D. G., The M06 Suite of Density Functionals for Main Group Thermochemistry, Thermochemical Kinetics, NonCovalent Interactions, Excited States, and Transition Elements: Two New Functionals and Systematic Testing of Four M06-Class Functionals and 12 other Functionals. Theoretical Chemistry Accounts 2008, 120 (1), 215-241.

59. Ngo, S. T.; Tam, N. M.; Pham, M. Q.; Nguyen, T. H., Benchmark of Popular Free Energy Approaches Revealing the Inhibitors Binding to SARS-CoV-2 Mpro. J. Chem. Inf. Model. 2021, 61 (5), 2302-2312.

60. Chemicalize was used for prediction of chemical properties. https://chemicalize.com/, developed by ChemAxon.

61. Buch, I.; Giorgino, T.; De Fabritiis, G., Complete Reconstruction of an Enzyme-Inhibitor Binding Process by Molecular Dynamics Simulations. Proc Natl Acad Sci U S A 2011, 108 (25), 10184-10189.

62. Świderek, K.; Moliner, V., Revealing the Molecular Mechanisms of Proteolysis of SARS-CoV-2 Mpro by QM/MM Computational Methods. Chemical Science 2020, 11 (39), 10626-10630.

63. Ramos-Guzmán, C. A.; Ruiz-Pernía, J. J.; Tuñón, I., Unraveling the SARS-CoV-2 Main Protease Mechanism Using Multiscale Methods. ACS Catal 2020, 10 (21), 12544-12554.

64. Ramos-Guzmán, C. A.; Ruiz-Pernía, J. J.; Tuñón, I., Multiscale Simulations of SARS-CoV-2 3CL Protease Inhibition with Aldehyde Derivatives. Role of Protein and Inhibitor Conformational Changes in the Reaction Mechanism. ACS Catal 2021, 11 (7), 4157-4168.

65. Ramos-Guzmán, C. A.; Ruiz-Pernía, J. J.; Tuñón, I., A Microscopic Description of SARS-CoV-2 Main Protease Inhibition with Michael Acceptors. Strategies for Improving Inhibitor Design. Chem. Sci. 2021, 12 (10), 3489-3496.

66. Ramos-Guzmán, C. A.; Ruiz-Pernía, J. J.; Tuñón, I., Computational simulations on the binding and reactivity of a nitrile inhibitor of the SARS-CoV-2 main protease. Chem. Commun. 2021.

67. Buller, A. R.; Townsend, C. A., Intrinsic Evolutionary Constraints on Protease Structure, Enzyme Acylation, and the Identity of the Catalytic Triad. Proc Natl Acad Sci U S A 2013, 110 (8), E653-E661. 
68. Wang, Y.-H.; Zhang, F.; Diao, H.; Wu, R., Covalent Inhibition Mechanism of Antidiabetic Drugs-Vildagliptin vs Saxagliptin. ACS Cat 2019, 9 (3), 2292-2302.

69. Zanetti-Polzi, L.; Smith, M. D.; Chipot, C.; Gumbart, J. C.; Lynch, D. L.; Pavlova, A.; Smith, J. C.; Daidone, I., Tuning
Proton Transfer Thermodynamics in SARS-CoV-2 Main Protease: Implications for Catalysis and Inhibitor Design. J. Phys. Chem. Lett. 2021, 12 (17), 4195-4202. 